\title{
Letter to the Editor: Resonance assignments of the double-stranded RNA-binding domains of adenosine deaminase acting on RNA 2 (ADAR2)
}

\author{
Richard Stefl $^{\mathrm{a}, *}$, Lenka Skrisovska ${ }^{\mathrm{a}}$, Ming $\mathrm{Xu}^{\mathrm{b}}$, Ronald B. Emeson ${ }^{\mathrm{b}}$ \& Frederic H.-T. \\ Allain $^{\mathrm{a}, *}$ \\ ${ }^{\mathrm{a}}$ Institute of Molecular Biology and Biophysics, Swiss Federal Institute of Technology Zürich, ETH-Höng- \\ gerberg, CH-8093 Zürich, Switzerland; ${ }^{b}$ Department of Pharmacology, Vanderbilt University, Nashville, \\ TN 37232, U.S.A.
}

Received 20 September 2004; Accepted 2 November 2004

Key words: NMR resonance assignment, RNA editing, RNA-binding domains

\section{Biological context}

Adenosine deaminases that act on RNA (ADARs) convert adenosine to inosine (A-to-I) by hydrolytic deamination in cellular and viral RNA transcripts containing either perfect or imperfect RNA duplexes (Bass, 2002). A-to-I editing can be either specific or non-specific, deaminating up to $50 \%$ of the adenosine residues within a perfect RNA duplex, while modifying a single or limited set of adenosine residues within imperfect double-stranded RNA (dsRNA) regions containing bulges, loops, and mismatches (Bass, 2002). The majority of non-selective editing occurs in untranslated regions (UTRs) and introns where large regular duplexes are formed. Such modifications can modulate gene silencing triggered by intramolecular structures in mRNA (Tonkin and Bass, 2003), the nuclear retention of hyperedited RNA transcripts, or participate in the antiviral response by extensive modification of viral RNAs. Selective editing has been shown to take place largely within codons, so that multiple RNA and protein isoforms can be created from a single genomic locus. For example, ADARs have been shown to produce functionally important isoforms for numerous proteins involved in synaptic neurotransmission, including ligand and voltage-gated ion channels and G-protein coupled receptors (Bass, 2002).

Like many RNA-binding proteins, ADARs display a modular domain organization, having two or three tandem copies of double-stranded RNA-binding domain (dsRBDs) at its $\mathrm{N}$-terminal, and a C-terminal adenosine deaminase domain. The dsRBDs of

*To whom correspondence should be addressed. E-mails: \{allain, stefl\}@mol.biol.ethz.ch
ADARs play an important role in modulating the editing selectivity of ADARs (Carlson et al., 2003). To gain insight into this intriguing protein-RNA recognition process, we have initiated an NMR study of the two dsRBDs of rat ADAR2 (74-301) (designated dsRBD12). Here, we report ${ }^{1} \mathrm{H},{ }^{13} \mathrm{C}$, and ${ }^{15} \mathrm{~N}$ resonance assignments of the dsRBD12 of ADAR2.

\section{Methods and results}

Initial attempts to study the 228-residue $\mathrm{N}$-terminal dsRBD12 of rat ADAR2 (74-301) failed due to the low solubility of the protein in common NMR buffers. To enhance the solubility limit of dsRBD12, a noncleavable solubility-enhancement tag, GB1 (Zhou et al., 2001), was fused to the protein. dsRBD12 was cloned into pET30-GBFusion 1 vector yielding N-terminal GB1-tagged and C-terminal His-tagged construct of dsRBD12 (294 residues; designated GB1-dsRBD12). The protein was overexpressed in BL21(DE3) E. coli in $100 \%$ and $60 \% \mathrm{D}_{2} \mathrm{O}$ minimal medium $(0.51)$ containing $\left[{ }^{13} \mathrm{C}_{6}\right]$ glucose and ${ }^{15} \mathrm{NH}_{4} \mathrm{Cl}$ in order to obtain a $\sim 85 \%$ and $\sim 50 \%$ deuterated $\left({ }^{2} \mathrm{H}\right),\left[{ }^{13} \mathrm{C},{ }^{15} \mathrm{~N}\right]$-labeled proteins, respectively. Cells were grown at $37{ }^{\circ} \mathrm{C}$ to $\mathrm{OD}_{600} \sim 1$ and induced with $1 \mathrm{mM}$ IPTG. The protein was purified under denaturating conditions and refolded into native buffer on Ni-NTA affinity column. The refolded GB1dsRBD12 provides the same $\left[{ }^{1} \mathrm{H}_{-}{ }^{15} \mathrm{~N}\right]$-TROSY spectrum as the one purified under native conditions (data not shown). The protein was concentrated to $\sim 0.8 \mathrm{mM}$ in $250 \mu \mathrm{l}$ of $50 \mathrm{mM}$ sodium phosphate buffer ( $\mathrm{pH} 8.0$ ) containing $200 \mathrm{mM} \mathrm{NaCl}$.

With the same protocol, N-terminal His-tagged $\left[{ }^{13} \mathrm{C}\right.$, $\left.{ }^{15} \mathrm{~N}\right]$-labeled dsRBD1 (74-147) and dsRBD2 (231-301) 
fragments were also expressed, purified, and refolded, separately. These individual domains were important to confirm the resonance assignment of the long protein construct, because dsRBD1 and dsRBD2 share 52\% sequence identity and contain repeated residues in the sequence such as leucines and lysines, which cause chemical shift degeneracy.

All the NMR experiments were conducted at $20{ }^{\circ} \mathrm{C}$ using Bruker Avance-900 and DRX-750, 600, and $500 \mathrm{MHz}$ spectrometers. The following spectra were recorded on a $\left[{ }^{2} \mathrm{H}(85 \%),{ }^{13} \mathrm{C},{ }^{15} \mathrm{~N}\right]$-labeled GB1-dsRBD12 sample for assignment of the backbone and $\mathrm{C}_{\beta}$ resonances: $\left[{ }^{1} \mathrm{H},{ }^{15} \mathrm{~N}\right]$-TROSY (Figure 1), $\left[{ }^{1} \mathrm{H},{ }^{15} \mathrm{~N}\right]$-TROSY-HNCA (Salzmann et al., 1998), $\left[{ }^{1} \mathrm{H},{ }^{15} \mathrm{~N}\right]-$ TROSY-HNCACB (Salzmann et al., 1999), 3D NOESY $-\left[{ }^{1} \mathrm{H},{ }^{15} \mathrm{~N},{ }^{1} \mathrm{H}\right]-\mathrm{TROSY}$ (Pervushin et al., 1999). Side chain resonance assignments were achieved using a 3D NOESY- $\left[{ }^{1} \mathrm{H},{ }^{15} \mathrm{~N},{ }^{1} \mathrm{H}\right]$-TROSY and a $3 \mathrm{D}\left[{ }^{1} \mathrm{H},{ }^{13} \mathrm{C}\right.$, $\left.{ }^{1} \mathrm{H}\right]$-NOESY experiments ran on a $\left[{ }^{2} \mathrm{H}(50 \%),{ }^{13} \mathrm{C},{ }^{15} \mathrm{~N}\right]-$ labeled GB1-dsRBD12 sample. These latter assignments were made by comparison with the spectra of the individual domains where the side-chain resonances were assigned using a 3D $\left[{ }^{1} \mathrm{H},{ }^{15} \mathrm{~N},{ }^{1} \mathrm{H}\right]$-NOESY, a 3D $\left[{ }^{1} \mathrm{H}\right.$, $\left.{ }^{13} \mathrm{C},{ }^{1} \mathrm{H}\right]$-NOESY, and a 3D HCCH-TOCSY (Bax and Grzesiek, 1993) experiments on $\left[{ }^{13} \mathrm{C},{ }^{15} \mathrm{~N}\right]$-labeled dsRBD1 and dsRBD2 samples. Aromatic side chains were assigned using $2 \mathrm{D}\left[{ }^{1} \mathrm{H},{ }^{1} \mathrm{H}\right]$-TOCSY, $2 \mathrm{D}\left[{ }^{1} \mathrm{H},{ }^{1} \mathrm{H}\right]-$ NOESY.

\section{Extent of assignment}

The $\left[{ }^{1} \mathrm{H},{ }^{15} \mathrm{~N}\right]$-TROSY spectrum of the $\left[{ }^{2} \mathrm{H}(85 \%)\right.$, $\left.{ }^{13} \mathrm{C},{ }^{15} \mathrm{~N}\right]$-labeled GB1-dsRBD12 is shown in Figure 1 with indicated assignments. With the combined information from all heteronuclear experiments on the three different protein constructs, $99 \%$ of the backbone amide protons and ${ }^{15} \mathrm{~N}$ nuclei (prolines not counted), and $99 \%$ of the $\mathrm{C}_{\alpha}$ were assigned for the three structured domains of GB1-dsRBD12. Assignments could also be made for $35 \%$ of the 82 -residue linker (133-215), mostly for amino acids flanking prolines. The chemical shift of the latter residues (near random coil values) and the absence of NOEs indicate that this region is highly flexible and is likely to be unstructured. In total, $\sim 75 \%$ of the backbone were assigned of the entire protein sequence (1-294). This represents almost $100 \%$ of the resonances which appeared in the TROSY-type experiments. The assignment of side chain aliphatic ${ }^{1} \mathrm{H}$ and ${ }^{13} \mathrm{C}$ resonances is approximately $95 \%$ complete for the three structured domains, the remaining portion could not have been assigned due to resonance overlap. Aromatic proton assignment is $90 \%$ complete for the structured part of GB1-dsRBD12. ${ }^{1} \mathrm{H}$ chemical shifts

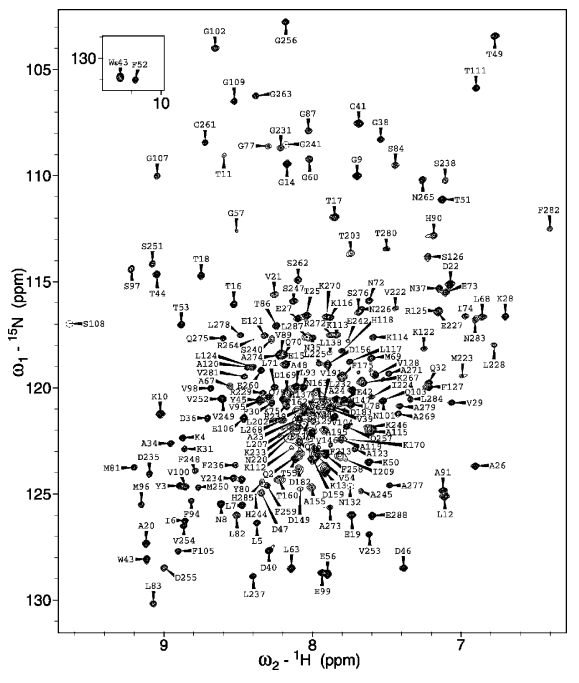

Figure 1. $\left[{ }^{1} \mathrm{H}-{ }^{15} \mathrm{~N}\right]$-TROSY spectrum of $\sim 0.8 \mathrm{mM} \quad\left[{ }^{2} \mathrm{H}(85 \%)\right.$, ${ }^{13} \mathrm{C},{ }^{15} \mathrm{~N}$-labeled GB1-dsRBD12 (32 kDa) in $50 \mathrm{mM}$ sodium phosphate buffer ( $\mathrm{pH} 8.0), 200 \mathrm{mM} \mathrm{NaCl}$, acquired at $293 \mathrm{~K}$ on a Bruker DRX-600 MHz spectrometer. The assignments are labeled by the one-letter code of amino acids accompanied by a sequence number. S108, N132, and G241 are only visible at a lower contour level and their positions are indicated by the dashed circles.

are referenced to internal 2,2-dimethyl- silapentane-5sulfonic acid (DSS), whereas ${ }^{13} \mathrm{C}$ and ${ }^{15} \mathrm{~N}$ chemical shifts are referenced indirectly to DSS, using absolute frequency ratios. Chemical shifts are deposited in the BioMagResBank Database (accession code BMRB$6280)$.

\section{Acknowledgements}

The work was supported by Swiss National Science Foundation and the Roche Research Fund for Biology at the ETH Zurich (to FHTA), by the National Institutes of Health (to RBE) and by European Molecular Biology Organization and Human Frontier Science Program postdoctoral fellowships to RS.

\section{References}

Bass, B.L. (2002) Annu. Rev. Biochem., 71, 817-846.

Bax, A. and Grzesiek, S. (1993) Acc. Chem. Res., 26, 131-138.

Carlson, C.B., Stephens, O.M. and Beal, P.A. (2003) Biopolymers, 70, 86-102.

Pervushin, K.V., Wider, G., Riek, R. and Wuthrich, K. (1999) Proc. Natl. Acad. Sci. USA, 96, 9607-9612.

Salzmann, M., Pervushin, K., Wider, G., et al. (1998) Proc. Natl. Acad. Sci. USA, 95, 13585-13590.

Salzmann, M., Wider, G., Pervushin, K., et al. (1999) J. Am. Chem. Soc., 121, 844-848.

Tonkin, L.A. and Bass, B.L. (2003) Science, 302, 1725.

Zhou, P., Lugovskoy, A.A. and Wagner, G. (2001) J. Biomol. NMR, 20, 11-14. 